\title{
Transición del manejo de plagas convencional hacia el agroecológico mediante la transferencia de técnicas de control integrado de plagas en tomate bajo cubierta en Concordia - Provincia de Entre Ríos, Argentina
}

\author{
The transition from chemical pest control to biological pest \\ management through the transfer of integrated pest management techniques \\ in greenhouse tomatoes in Concordia - Province of Entre Ríos, Argentina
}

Jorge Castresana ${ }^{*}$, Javier Rosenbaum ${ }^{1}$, Javier Rosenbaum ${ }^{2}$

\section{RESUMEN}

A lo largo del período 2015 - 2017 se dio comienzo a una transición del manejo convencional de plagas, es decir, basado únicamente en la aplicación de productos químicos sintéticos de amplio espectro, a un manejo agroecológico mediante la transferencia de diferentes técnicas de control integrado de plagas y enfermedades (MIPE). Una de las técnicas utilizadas fue controlar la mosca blanca de los invernaderos T. vaporariorum West. mediante la liberación de un parasitoide de mosca blanca Encarsia formosa Gahan, en combinación con la técnica de trampeo masivo efectuada por medio de bandas cromotrópicas adhesivas amarillas. En lo que respecta al control de la polilla del tomate Tuta absoluta, se realizó un trampeo masivo por medio de trampas de luz LED con feromonas. Todas estas técnicas estuvieron complementadas con la aplicación puntual, en caso de ser necesario, de insecticidas de síntesis química selectivos y de origen botánico compatibles con la conservación de depredadores y parasitoides que aparecen en el cultivo en forma espontánea. Durante los tres años de trabajo en los que se aplicaron diversas técnicas de manejo integrado de plagas y enfermedades (MIPE), se logró no solo que no disminuyera la producción a causa de daños, sino también que el productor se convirtiera en protagonista de este cambio propuesto, el cual da como resultado una producción de tomate con mínimos residuos químicos.

Palabras clave: mosca blanca, polilla del tomate, trampas, LEDs, captura masiva, transición agroecológica.

\begin{abstract}
During the period from 2015 to 2017 a transition from conventional to sustainable agriculture has begun, that is, a change from conventional agriculture based solely on the application of broad-spectrum pesticides to biological pest control which involves a variety of strategies used for Integrated Pest and Disease Management (IPDM). One of these strategies was to control the greenhouse whitefly $\mathrm{T}$. vaporariorum West by releasing the greenhouse whitefly parasite Encarsia formosa Gahan in combination with mass trapping through yellow sticky traps into crops. In relation to control of the tomato leafminer, Tuta absoluta, a mass trapping equipped with LEDs combined with pheromones was carried out.

All the above strategies were complemented, in case it had been required, with selective and botanical pesticides without lethal effects on predators and parasitoids which could have naturally appeared in crops.

The diversity of strategies of Integrated Pest and Disease Management (IPDM) applied in this research not only prevented the decrease of production for damage but also stressed the importance of the farmer role throughout this process resulting in a tomato production with minimal chemical residue.
\end{abstract}

Key word: whitefly, tomato leafminer, traps, LEDs, massive trapping, agroecological transition.

\section{Introducción}

En el departamento de Concordia las explotaciones hortícolas utilizan fundamentalmente mano de obra familiar en una superficie de 26,6 hectáreas, de las cuales 1,6 ha aproximadamente suelen ser bajo cubierta (invernaderos) y las restantes 25 ha corresponden a cultivos a campo abierto. Ambas superficies coexisten a lo largo del año (C. Barreto, EEA INTA Concordia, com. pers.). Si bien la producción hortícola total del departamento de Concordia es muy pequeña,

\footnotetext{
1 Estación Experimental Agropecuaria INTA Concordia. C.P. 3200, Estación Yuquerí. Concordia, Entre Ríos, Argentina

2 AER INTA Concepción del Uruguay. C.P. 3260, 9 de Julio No 158. Concepción del Uruguay, Entre Ríos, Argentina.

* Autor por correspondencia: castresana.jorge@correo.inta.gob.ar
} 
considerando las hectáreas de superficie cultivadas, abarca una amplia diversidad de especies: tomate, pimiento, batata, lechuga, acelga, rúcula, melón y sandía (MCBA, 2011). Sin embargo, esta gran variedad de especies que se destina en su totalidad al consumo local no logra cubrir la alta demanda de hortalizas. Dada esta circunstancia, y sumado a que en la actualidad existen pequeños productores que cuentan con una estructura productiva que podríamos calificar de "buena" a "muy buena" en el cultivo de tomate bajo cubierta debido al nivel tecnológico que se requiere (uso de semillas híbridas, manejo eficiente del agua y fertilización por medio del fertirriego), podríamos decir que aún persiste una carencia en el empleo del MIPE. Este implica la utilización de prácticas agroecológicas para el manejo simultáneo de todos los agentes perjudiciales en el cultivo (Prokopy \& Kogan, 2003; Ehler, 2006).

Dentro de estas prácticas se encuentra el "control biológico", el cual favorece la reducción de las poblaciones de plagas por enemigos naturales (depredadores, parasitoides y entomopatógenos) (Moschetti, 2003). Una de las estrategias del control biológico es por inundación, definida por Van Driesche \& Bellows Jr., 1996, como "las liberaciones de un número muy elevado de organismos vivos, nativos o introducidos, como agentes de control biológico para reducir la población de la plaga a corto plazo cuando la densidad alcanza niveles de daño económico". Esta estrategia es muy similar a la de la aplicación de productos fitosanitarios, tanto en sus objetivos como en su formulación y aplicación. Con respecto a los agentes entomófagos utilizados fueron insectos parasitoides. A diferencia de los parásitos, los parasitoides siempre matan a sus hospedadores. Sin embargo, el hospedador puede completar la mayor parte de su ciclo de vida antes de morir (Van Driesche et al., 2007).

Otra técnica que integra el MIPE es el trampeo masivo ("mass trapping"), el cual comprende el uso de una cantidad de trampas por hectárea que permite disminuir la densidad de una plaga por medio de la atracción y muerte ("attract and kill") de una alta proporción de individuos (El-Sayed et al., 2006). El trampeo puede ser por medio de: (1) la confusión sexual, que se basa en interrumpir la comunicación entre los insectos macho y hembra a través de la saturación del medio con feromona sexual, para disminuir o impedir las cópulas y, por lo tanto, evitar la puesta de las hembras y que haya descendencia de la especie (Weatherston, 1990); (2) el trampeo físico, basado en la atracción cromotrópica que diversos colores ejercen sobre determinadas especies de insectos: trampas amarillas para áfidos (pulgones) y aleuródidos (moscas blancas) (Qiu \& Ren, 2006; Gu et al., 2008) o azules para ciertos trips (Brodsgaard, 1993); y (3) el estímulo lumínico, con base en la atracción de la iluminación nocturna artificial, especialmente, con alta emisión de luz en la región del UV (Frank, 2006).

Por lo tanto, el logro de estas prácticas aportaría un valor agregado al producto en comparación con otros, lo cual implicaría una mejora en la rentabilidad del productor.

Considerando los beneficios de estas técnicas y el escaso número de productores que realizan este tipo de cultivos que no generan grandes volúmenes de tomate fresco, el objetivo del trabajo fue poner en práctica un proceso de transición de la horticultura convencional hacia otro que utilice métodos que minimicen el uso de productos fitosanitarios mediante un correcto manejo del MIPE con un productor de Concordia.

\section{Materiales y Métodos}

El manejo integrado de plagas y enfermedades MIPE se aplicó en un invernadero de plástico a dos aguas a lo largo del periodo 2015-2017. Este invernadero pertenece al agricultor de producción comercial Víctor Campeglia. Los monitoreos y la transferencia de tecnología que se realizaron están enmarcados en una actividad dentro del Proyecto Regional con Enfoque Territorial del nordeste de Entre Ríos (PRET), de la Estación Experimental Agropecuaria Concordia del INTA (EEA Concordia), Proyecto específico INTA - PNHFA 1106082. "Tecnología apropiada para la sustentabilidad con énfasis en sistemas hortiflorícolas con énfasis en cultivos protegidos", y en la Red de Agroecología REDAE de INTA. La superficie del invernadero era de $800 \mathrm{~m}^{2}$. El híbrido de tomate redondo indeterminado que se utilizó era Elpida F1. La densidad promedio de plantación fue de 2,5 plantas por $\mathrm{m}^{2}$. Las fechas de trasplante variaron entre el 10 de marzo del 2015, el 6 de marzo en el 2016 y, por último, el 13 de marzo en el 2017, mientras que las plantaciones se mantuvieron en producción hasta fines de diciembre cuando se retiró el cultivo. 


\section{Manejo integrado de plagas para tomate bajo cubierta}

Como punto de partida del MIPE fue imprescindible que se realizaran no solo los monitoreos, sino también un recorrido por el invernadero, con la finalidad de observar el estado del cultivo en general y detectar posibles síntomas de plagas y/o enfermedades. Los monitoreos fueron efectuados semanal o quincenalmente, dependiendo de la estación del año en que hicieron.

Los monitoreos llevados a cabo en cada visita (Figura 1) permitieron determinar la presencia de alguna plaga, en cuyo caso se observaría si esta estaba próxima a llegar a un umbral de daño que diera el tiempo suficiente para tomar la mejor decisión para su control. El método de monitoreo es básicamente el propuesto por (Polack \& Mitidieri, 2005).

La mosca blanca de los invernaderos, $T$. vaporariorum Westwood, es considerada una de las plagas principales del tomate bajo cubierta y su control fue realizado por medio de varias herramientas, entre las que se encuentra el control biológico a través de la liberación del parasitoide Encarsia formosa (Gahan) como complemento del trampeo masivo con bandas cromotrópicas adhesivas amarillas, así como la aplicación de tratamientos con insecticidas químicos y/o botánicos compatibles con la fauna auxiliar.

En la semana posterior al trasplante se comenzaron a realizar los monitoreos con una frecuencia semanal a fin de determinar el umbral de daño económico de la mosca blanca. En este caso, solo estuvo presente la especie T. vaporariorum

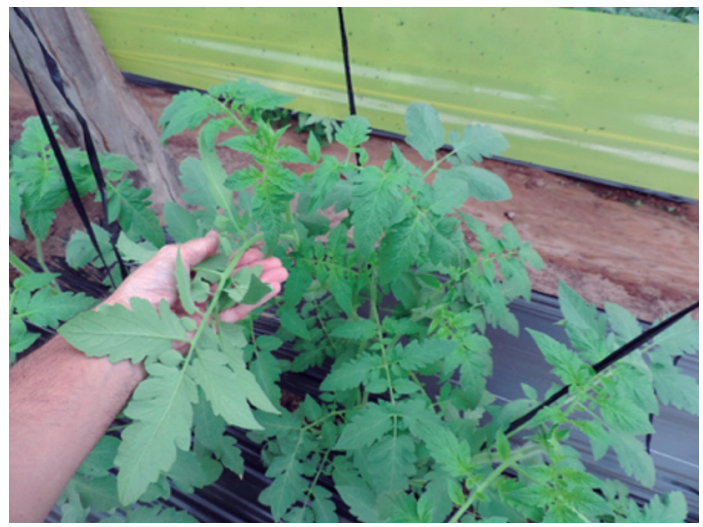

Figura 1. Monitoreo directo de plagas en cultivo de tomate.
10 adultos/hoja y 8 ninfas/folíolo en el cultivo de tomate. Una vez realizado el trasplante, se instalaron 10 bandas adhesivas cromotrópicas amarillas de 4 metros de largo cada una (trampeo masivo) con el propósito de capturar adultos de mosca blanca y evitar su establecimiento.

En el transcurso del ciclo del cultivo de tomate, las bandas para trampeo masivo fueron levantadas a $25 \mathrm{~cm}$ sobre el dosel del cultivo para mejorar la eficiencia de la captura de adultos de moscas blancas (Figura 2). A pesar de ello, se continuaron los monitoreos semanales para confirmar el establecimiento de la mosca blanca mediante la observación de ninfas en folíolos, y en ese momento se determinó la liberación de pupas de parasitoide (con una frecuencia quincenal) a partir del mes de agosto hasta noviembre. Estas pupas fueron distribuidas por medio de tarjetas (Figura 3) en las zonas donde se encontraban las ninfas, en la parte baja de la planta (hojas más viejas de la planta), como complemento de la técnica de trampeo masivo.

En este caso, una manera rápida de evaluar si el control biológico resultaba eficaz era a través

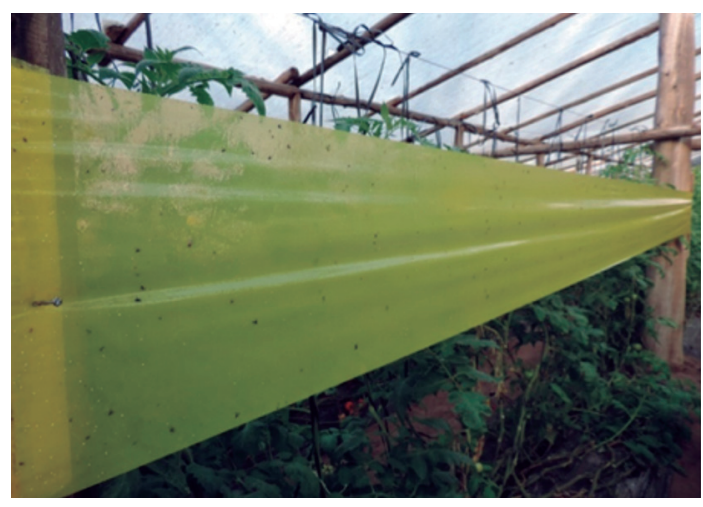

Figura 2. Bandas cromotrópicas adhesivas amarillas en invernadero.

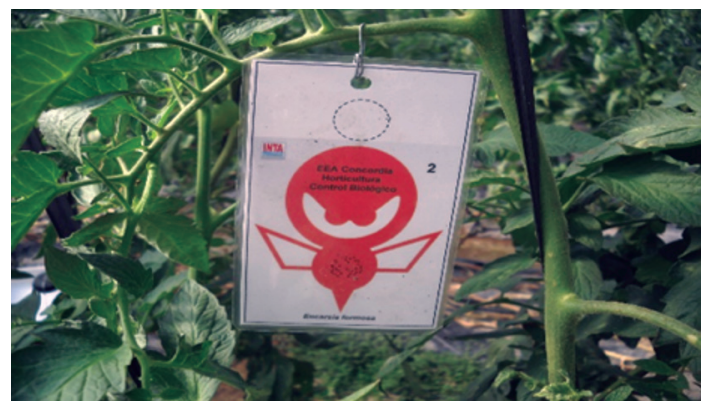

Figura 3. Tarjeta de liberación de Encarsia formosa en invernadero. 
del registro del nivel de parasitismo de $E$. formosa en el cultivo (observar la presencia de pupas de mosca blanca negras) (Figuras 4 y 5). Finalmente, se realizaron cuatro liberaciones en total, a razón de 6 pupas por $\mathrm{m}^{2} \mathrm{de}$ E. formosa. Posteriormente, los monitoreos efectuados determinaron si el número de adultos y ninfas se encontraba cerca del umbral de daño, lo cual justificaría realizar-como último recurso de control de la plaga- algún tratamiento con insecticida de síntesis química selectivo o botánico compatible con la fauna auxiliar,



Figura 4. Encarsia formosa parasitando ninfa de mosca blanca.



Figura 5. Presencia de pupas negras parasitadas por Encarsia formosa. para evitar perjudicar a los enemigos naturales liberados. Al mes de la primera liberación se hizo la primera evaluación de la instalación del parasitoide utilizando la técnica de presencia/ ausencia de pupas de mosca blanca parasitadas anteriormente explicada.

El promedio de ninfas de mosca blanca monitoreado indica una medida general del grado de infestación que existe en el cultivo, el cual puede ser total o sectorizado. A fin de determinar el porcentaje de parasitismo, se recolectaron folíolos con ninfas de mosca blanca y se calculó por medio de lupa estereoscópica de 40x la proporción de pupas (parasitadas o no). Estas evaluaciones se realizaron semanalmente hasta el final del cultivo. En este sentido, es fundamental que el monitoreador se mantenga atento y observe no solo en hoja sino también en fruto el desarrollo de algún síntoma de fumagina.

En cuanto a la otra plaga principal del tomate bajo cubierta, la polilla del tomate, Tuta absoluta (Meyrick), se aplicó el mismo manejo de las moscas blancas, que incluye varias herramientas, entre las que se encuentran: 1) el monitoreo (indirecto y directo); 2) el trampeo masivo de machos adultos con trampas de luz LED autónomas por medio de un panel solar, cebadas con feromonas sexuales con la finalidad de lograr el efecto de atraer y capturar a los adultos macho de la polilla (Figura 6); y 3) el uso de insecticidas de diferentes orígenes, por ejemplo, de síntesis química (selectivos), botánicos y de microorganismos.

Con referencia al monitoreo semanal, se puede detectar rápidamente la presencia del minador de la hoja, Tuta absoluta, en el cultivo. Ello se logra

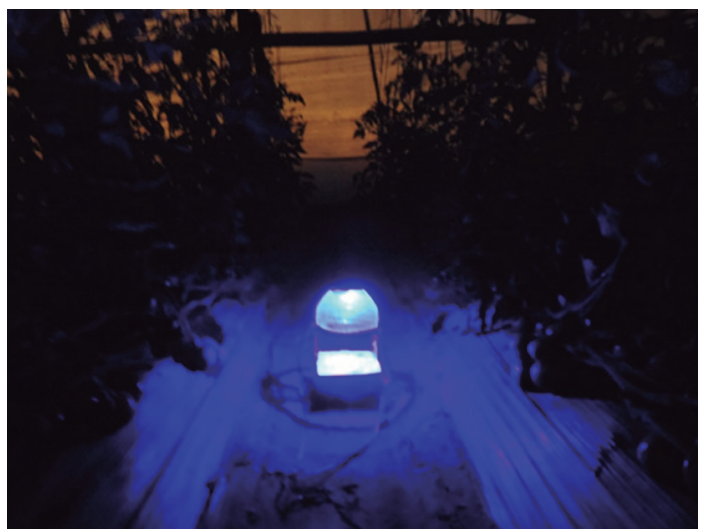

Figura 6. Trampa de luz LED autónoma con panel solar. 
mediante el monitoreo indirecto, el cual se realiza con la captura de machos en la trampa delta cebada con feromona sexual (Figura 7), o el monitoreo directo, a través de la observación de folíolos con una lupa de campo 30x que permite visualizar la presencia de larva en la galería, en cuyo caso, se verifica si se encuentra o no parasitada. Este último monitoreo comparado con el anterior resulta más conveniente por su alta correlación con la densidad de la plaga.

Es importante conocer el porcentaje de larvas de T. absoluta muertas o parasitadas sobre el total de larvas vivas a los fines de determinar el nivel de parasitismo. Asimismo, se debe aclarar que se utilizó otra herramienta de manejo: el "trampeo masivo de adultos macho de polilla del tomate", que comprende el uso de trampas de agua que emiten dos señales, una de origen químico (feromona sexual) y otra de origen lumínico (luz LED), ambas funcionando en forma sinérgica para atraerlos.

Este tipo de trampa es muy efectiva en circunstancias en las que los niveles poblacionales son bajos, ya que al aumentar la captura de adultos machos, se retrasa la fecundación de la hembra. Sin embargo, cuando estamos en presencia de altos niveles de plaga, la captura de machos resulta obsoleta porque no evita la fecundación de hembras.
Es necesario explicar que, aún en el caso de que los niveles de plaga continúen aumentando a pesar de la aplicación de un trampeo masivo, este debe seguir siendo utilizado como complemento de tratamientos preventivos a base de microorganismos Bacillus thuringiensis (Berliner) var. kurstaki y aizawai, Beauveria bassiana (Bals.), Metharizium anisopilae (Metsch.) o insecticidas botánicos, como el aceite de neem y extracto de ajo. Si la aplicación de dichos productos preventivos no provocara una disminución del nivel de la polilla y continuara incrementándose hacia su umbral de daño, se debería optar por una estrategia y realizar tratamientos curativos con productos de bajo impacto con principios activos como spinosad -rynaxipir- metaflumizona.

Asimismo, en el caso de que se observara la presencia de orugas defoliadoras - por ejemplo, del género Spodoptera- en los folíolos, se podrán realizar tratamientos similares a los utilizados para la polilla del tomate con productos preventivos y/o curativos de acuerdo con el nivel de daño.

Dentro del cultivo de tomate pueden aparecer otras plagas que se localizan en focos, por ejemplo, la mosca minadora de la hoja Liriomysa spp. y pulgones, cuya especie más observada es Macrosiphum euphorbiae (Thomas). Ambas

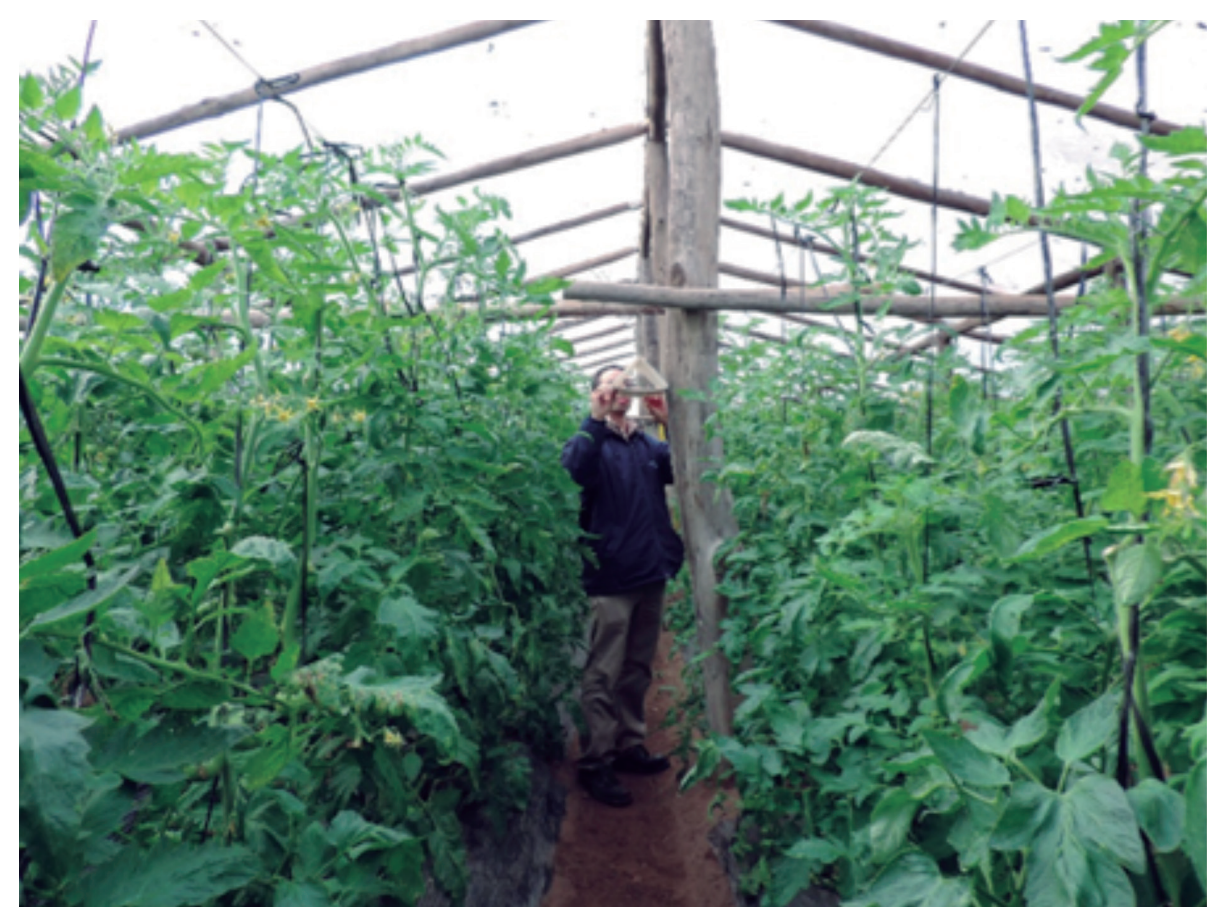

Figura 7. Monitoreo indirecto de la polilla del tomate. 
plagas pueden ser controladas por depredadores y parasitoides. Sin embargo, si el nivel de parasitismo es deficiente y el nivel de las plagas aumenta, se deberá realizar algún tratamiento con productos fitosanitarios selectivos.

Por último, en este cultivo pueden presentarse focos de ácaros, como Tetranychus urticae (Koch) o arañuela roja y Aculops lycopersici (Masse) o ácaro del bronceado del tomate, cuyo desarrollo se ve favorecido por las temperaturas elevadas. Por lo tanto, el foco localizado debe tratarse en forma preventiva con azufre, tierra de diatomeas o productos botánicos como aceite de neem, aceite de canela, jabón potásico, esteres de sacarosa y, finalmente, con acaricidas de síntesis química que tengan como principio activo spiromesifen, el cual resulta compatible con ácaros depredadores.

Una vez trasplantado el cultivo, se deben realizar tratamientos preventivos con extracto de ajo y/o aceite de neem, con el fin de repeler orugas cortadoras o grillos que pudieran cortar el cuello del plantín y afectar el stand de plantas. Asimismo, estos tratamientos favorecen la repelencia de los trips: 1) Caliothtips phaseoli (Hood) o trips del poroto que aparece y produce daño de alimentación en las hojas y no transmite el virus de la peste negra Tomato Spotted Wild Virus (TSWV) y 2) Frankliniella occidentalis (Pergande) o trips occidental de las flores que no solo produce daño por alimentación, sino que también transmite el virus de la peste negra durante el primer mes, etapa en la que el cultivo es más susceptible. En caso de que aparezcan plantas con síntomas, estas deben retirarse.

Si se manifestara alguna enfermedad, la persona encargada del monitoreo debe determinar la conveniencia de aplicar algún tratamiento para combatirla ante los primeros síntomas o condiciones ambientales que favorezcan su aparición. Los fungicidas que se apliquen deberán elegirse de acuerdo con su selectividad frente al patógeno identificado.

\section{Resultados y Discusión}

El estudio se inició a principios de marzo del año 2015 y se comenzó a tomar datos del invernadero una vez que el productor permitió realizar un limitado manejo integrado de plagas y de enfermedades propuesto (1 $1^{\text {er }}$ año de transición), mientras que, al año siguiente, se logró ampliar este manejo integrado de plagas y de enfermedades ( $2^{\text {do }}$ año transición) en este mismo invernadero con cultivo de tomate. En el último año de estudio, 2017 (3er año de transición), se mantuvo un nivel bajo de plagas. Se pudo observar que las que aparecieron en el cultivo de tomate en 2015 fueron similares a las que se presentaron en los sucesivos años del estudio.

\section{Plagas}

\section{Adultos de la mosca blanca}

La única especie de mosca blanca identificada fue $T$. vaporariorum (Westwood). Esta especie se monitoreó durante los tres años del estudio y en el momento en que su presencia estuvo cerca de llegar al umbral de daño, se realizaron liberaciones de la avispita parásita $E$. formosa para su control biológico.

Los monitoreos llevados a cabo en los invernaderos en estos años (Figura 8) mostraron que al inicio de las tres campañas los niveles de mosca blanca no fueron elevados. Teniendo en cuenta lo descrito por Van Roermund \& Van Lenteren (1992), la duración en días de cada generación varía de acuerdo principalmente con la temperatura y la calidad de la planta hospedante. En el año 2015 se registró un aumento del número de ninfas de mosca blanca y se decidió liberar parasitoides en forma curativa. Estas liberaciones se realizaron a principios del mes de agosto y luego desde octubre hasta final del cultivo.

En la campaña 2015, al momento de liberar el parasitoide, el promedio de adultos de mosca blanca en el invernadero se encontró por debajo del umbral de daño, es decir, 6 adultos/hoja. En el año 2016, si bien se repitió el manejo integrado de plagas, al momento de realizar la suelta del



Figura 8. Evolución de adultos de mosca blanca T. vaporariorum por hoja en tomate a lo largo de las campañas 2015-2017. 
parasitoide, el promedio de adultos de mosca blanca en el invernadero se ubicó por debajo del umbral de daño, es decir, 3 adultos/hoja. En el mes de septiembre de ese último año y luego de sucesivos monitoreos semanales en el invernadero, se observó que el pico de la plaga fue de un promedio de 8 adultos de mosca blanca/hoja, lo cual arrojó un nivel más bajo. Este resultado pudo haber tenido dos causas: 1) las abundantes precipitaciones acontecidas en el año, que retrasaron la llegada de la plaga al cultivo de tomate bajo cubierta. Esto coincide con los resultados obtenidos por (Byrne \& Bellows, 1991), quienes manifestaron que los adultos de mosca blanca son considerados débiles voladores por su estrategia de vuelo, las características de sus alas y la frecuencia del aleteo; y 2) las bandas adhesivas cromotrópicas amarillas que fueron ubicadas estratégicamente en los sectores donde se registraron los focos de mosca blanca en la campaña 2015, con las cuales hubo un aumento en la eficiencia en la captura de adultos de este insecto.

Los resultados logrados son sustentados por Vernon \& Gillespie (1990), quienes expresaron que, en el caso de las moscas blancas, existe un comportamiento de vuelo a corta distancia orientado hacia las trampas por su atracción por el color amarillo.

En el año 2017 se continuó con el manejo integrado de plagas. Sin embargo, a diferencia de los años anteriores, no se realizaron sueltas del parasitoide por la muy baja presencia de mosca blanca. Esto pudo deberse a que el uso de esas trampas ha sido objeto de investigación en las últimas décadas, lo que determinó su incorporación como componentes principales en varios programas de manejo de plagas bajo cubierta (Kaas, 2005; Park et al., 2011).

\section{Parasitismo de la mosca blanca}

Los porcentajes de parasitismo logrados por E. formosa durante las dos primeras campañas en las que se realizaron las liberaciones están representados en la Figura 9. Los monitoreos semanales muestran que la cantidad de mosca blanca fue más elevada en el año 2015 en comparación el 2016 y 2017. Esto propició que, en presencia de menores niveles de plaga, se produjera un mayor parasitismo de E. formosa, tal como lo demuestran los niveles hallados en el año 2016.

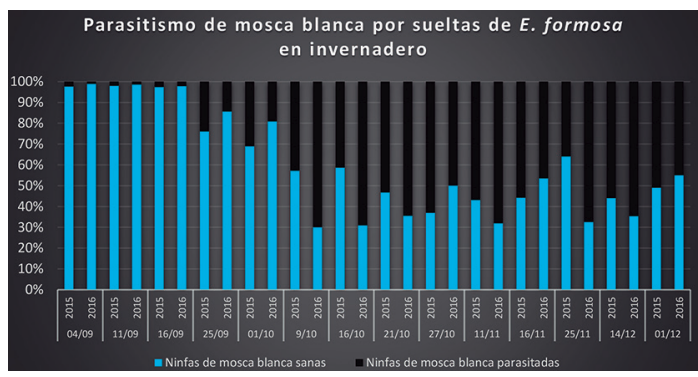

Figura 9. Evolución del parasitismo de las ninfas de mosca blanca T. vaporariorum por folíolo de tomate a lo largo de las campañas 2015-2016.

En conclusión, en la campaña 2015 el control de mosca blanca no fue satisfactorio como causa de la liberación del parasitoide sin el control eficiente de los adultos, por la mala ubicación de las bandas cromotrópicas adhesivas amarillas, sumado a la ineficacia de los tratamientos con insecticidas de síntesis química selectivos, que favoreció el incremento del nivel poblacional y la aparición de fumagina en hojas y en el caso del fruto en poca cantidad. A pesar de ello, se pudo revertir esta situación en la siguiente campaña del año 2016, ya que el control ejercido por el parasitoide fue satisfactorio por haberse complementado con el uso eficiente de las bandas cromotrópicas adhesivas amarillas, en combinación con insecticidas de origen botánico. En el año 2017 el nivel de mosca blanca fue prácticamente muy bajo. Los resultados del parasitismo de mosca blanca son apoyados por Soto et al. (2002), quienes demostraron que la aplicación de E. formosa en programas de control biológico en el cultivo de tomate bajo invernadero sobre ninfas de $2^{\circ}, 3^{\circ}$ y $4^{\circ}$ estadio de T. vaporariorum, puede lograr niveles de parasitismo que oscilan entre $37,4 \%$ y $64,7 \%$.

\section{Polilla del tomate}

En los datos obtenidos durante las tres campañas (2015-2017) aparece T. absoluta, lo cual era factible por la gran extensión de la plaga en esta zona y en el cultivo de tomate (Figura 10). En todas las campañas se monitoreó el parasitismo natural., Sse observó que durante todo el cultivo no hubo parasitismo, por lo tanto, fue necesario utilizar tratamientos preventivos con Bacillus thuringiensis var. kurstaki/aceite de neem, así como curativos mediante la aplicación de principios activos como 


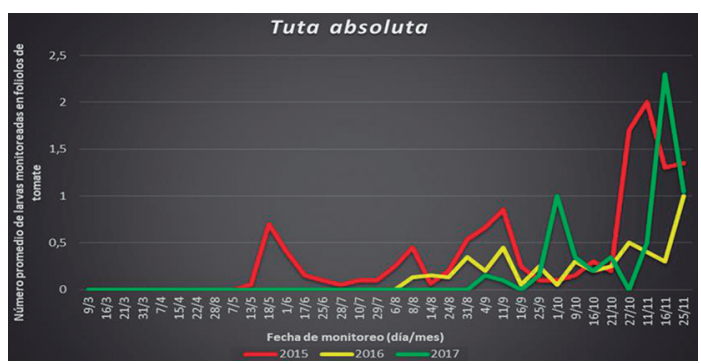

Figura 10. Evolución de adultos de polilla del tomate Tuta absoluta por hoja de tomate a lo largo de las campañas 2015-2016.

spinosad y rynaxipir, a fin de mantener los niveles de población bajos y no afectar a los enemigos naturales que pudieran encontrarse en el cultivo. En la campaña del año 2016, el nivel poblacional de T. absoluta fue considerablemente menor que en la campaña de 2015 , lo cual se pudo atribuir a dos causas: 1) importantes precipitaciones registradas en el mes de abril que retrasaron el establecimiento de la polilla y 2) la implementación de la técnica de trampeo masivo utilizando trampas cebadas con feromona sexual en combinación con luz LED. Esta última técnica fue la responsable de mantener los niveles bajos logrados en las campañas 2016 y 2017. Estos resultados son similares a los citados por Castresana et al. (2017), según los cuales el uso de trampas lumínicas cebadas con feromonas favoreció el trampeo de adultos de polilla del tomate.

\section{Pulgones}

En lo que se refiere al pulgón, si bien no se presentaron prácticamente inconvenientes, se pudieron observar bajos niveles de pulgones al principio de la instalación del cultivo a lo largo de todas las campañas en estudio.

\section{Monitoreo de otras plagas en el cultivo}

Con respecto a las otras especies de lepidópteros, estas tuvieron una importancia muy limitada solamente durante la campaña del año 2015, ya que se observó a mitad de abril una pequeña presencia focalizada de Spodoptera spp. que pudo controlarse eficazmente en ambas campañas mediante la aplicación de un tratamiento con principio activo rynaxipir.

En cuanto a los trips, sólo se encontraron adultos y algunas ninfas Caliothrips phaseoli en el período del trasplante en el mes de marzo en las tres campañas de los años 2015, 2016 y 2017. A pesar de observarse algunas plantas con síntomas de peste negra (TSWV) -esta especie de trips no lo transmite-, fue controlada por medio de la aplicación de jabón potásico (Hydralene $\left.{ }^{\circledR}\right)$ a una dosis del $2 \%$ en combinación con extracto de ajo (Renap 100®) a una dosis del 2\%. Asimismo, esta aplicación favoreció en forma indirecta el control de algunos pequeños focos de pulgones.

En ninguna de las campañas se observó el ácaro del bronceado del tomate. Sin embargo, en la campaña del año 2015 se pudo detectar la presencia de la arañuela roja, Tetranychus urticae (Koch), para cuyo control se realizó un tratamiento con jabón potásico (Hydralene $\left.{ }^{\circledR}\right)$ a una dosis del $2 \%$ en combinación con extracto de ajo (Renap $100 \circledR$ ) a una dosis del $2 \%$.

\section{Enfermedades}

Respecto de las enfermedades que se observaron en las campañas del año 2015 y 2017, podemos mencionar principalmente la mancha gris Botrytis cinérea, tizón foliar Sthemphyllium solani y el moho foliar del tomate Cladosporium fulvum.

Para la mayoría de los tratamientos fúngicos se utilizaron productos específicos, por ejemplo, estrobirulinas (trifloxistrobin y azoxistrobin), triazoles (tebuconazole), solos o combinados entre sí, y el fungicida botánico (aceite esencial de árbol de té Melaleuca artenifolia) usado en las tres campañas. Además, se aplicaron otros productos no específicos como hidróxido de cobre, sulfato de cobre pentahidratado para cicatrizar las heridas una vez realizado el desbrotado.

Considerando que las condiciones ambientales de los invernaderos durante la época otoño-invierno son las más favorables, ya que suelen alcanzar una humedad relativa del 100\% (humedad de saturación) -lo cual produce condensación de agua desde el techo provocando un goteo sobre las hojas (mojado)-, y además poseen una ventilación deficiente y una densidad de plantación alta, se convierten en el entorno propicio para el rápido desarrollo de los hongos ya mencionados. Dado que en ambas campañas fue necesario realizar varios tratamientos para controlar estas enfermedades, la aplicación de medidas culturales correctas a través de la instalación de un doble techo que evita el mojado de las hojas podría disminuir los riesgos y a la vez reducir el número de tratamientos preventivos. 
Se observó la aparición de bacterias Ralstonia solani en suelo en manchones y, con mayor intensidad, en el último camellón más cercano al zócalo del invernadero, lo cual exigió extremar las medidas culturales (desbrotado de hojas) a fin de no perder stand de plantas.

El virus TSWV se detectó en pocas plantas en las tres campañas en las que se realizó un manejo integrado de plagas.

\section{Tratamientos realizados}

En la Tabla 1, a modo de resumen, se muestran los tratamientos realizados en las tres campañas. Cada vez que se hace referencia a un tratamiento, nos referimos a una aplicación de producto, ya sea, insecticida, acaricida, fungicida y/o bactericida.

En el invernadero del productor asesorado por EEA INTA Concordia se observó un cambio de hábitos en cuanto a la disminución de tratamientos para el control de plagas y enfermedades, en comparación con lo realizado en los años anteriores. Este cambio fue confirmado mediante una encuesta que se le hizo al productor en el mes de febrero de 2017 y 2018, donde se obtuvo como dato que

Tabla 1. Número de tratamientos realizados a lo largo de las campañas 2015-2017.

\begin{tabular}{lccc}
\hline Productos & $\begin{array}{c}2015 \\
\mathrm{~N}^{\mathrm{o}} \text { Tratamientos }\end{array}$ & $\begin{array}{c}2016 \\
\mathrm{~N}^{\mathrm{o}} \text { Tratamientos }\end{array}$ & $\begin{array}{c}2017 \\
\mathrm{~N}^{\mathrm{o}} \text { Tratamientos }\end{array}$ \\
\hline Insecticidas & 20 & 13 & 6 \\
Fungicidas & 20 & 17 & 16 \\
\hline
\end{tabular}

cuanto más técnicas de MIPE eran aplicadas, más disminuía la cantidad de principios activos de insecticidas, acaricidas, fungicidas y bactericidas a lo largo del cultivo s (Tablas 1, 2 y 3).

\section{Conclusiones}

A lo largo de las dos campañas estudiadas en el cultivo de tomate bajo cubierta en la localidad de O. Magnasco, perteneciente al Departamento de Concordia-Provincia de Entre Ríos-Argentina, aparecieron plagas. Entre las principales se encuentran la mosca blanca, polilla del tomate casi de forma constante durante los dos años y el trips, pulgones solo en la primera semana del cultivo, así como lepidópteros Spodoptera, arañuela roja, detectados muy esporádicamente sin presentar ningún problema.

Gracias al MIPE, la utilización de insecticidas botánicos -de baja residualidad compatibles con los enemigos naturales- favoreció la instalación de la E. formosa liberada en diferentes dosis tanto preventivas como curativas, lo que da como resultado un buen control de las ninfas de mosca blanca. Esta técnica sumada al uso de bandas cromotrópicas adhesivas amarillas para el control de adultos de mosca blanca logró un buen complemento para el control integral de la plaga.

En lo que respecta a la polilla del tomate, en los monitoreos no se hallaron enemigos naturales ni parasitismo natural. A pesar de ello, el uso del trampeo masivo, realizado con trampas de luz LED combinadas con feromona sexual en complemento con insecticidas de bajo impacto,

Tabla 2. Resumen de principios activos aplicados para las diferentes plagas que se presentaron en ambas campañas.

\begin{tabular}{|c|c|c|c|c|}
\hline \multirow{2}{*}{ Principio activo/insecticida } & \multirow{2}{*}{ Plaga objetivo } & \multicolumn{3}{|c|}{$\mathrm{N}^{\mathrm{o}}$ de aplicaciones } \\
\hline & & 2015 & 2016 & 2017 \\
\hline Aceite de neem y canela + extracto de tagetes Experimental "Javelin" & & 1 & 3 & 2 \\
\hline Bacillus thuringiensis var. kurstaki & & 0 & 2 & 0 \\
\hline Lambda cihalotrin & Tuta absoluta polilla del tomate & 1 & 0 & 0 \\
\hline Rynaxypir & 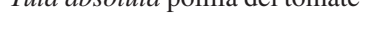 & 3 & 2 & 1 \\
\hline Spinosad & & 2 & 3 & 2 \\
\hline Cyazypir & & 2 & 0 & 0 \\
\hline Jabón potásico + extracto de ajo & Trialeurodes vaporariorum mosca & 1 & 3 & 1 \\
\hline Jabón potásico + acetamiprid & blanca de los invernaderos & 3 & 0 & 0 \\
\hline Tyocidam + clorfenapir & & 6 & 0 & 0 \\
\hline Tyocidam + abamectina & & 1 & 0 & 0 \\
\hline Total de aplicaciones realizadas & & 20 & 13 & 6 \\
\hline
\end{tabular}


Tabla 3. Resumen de principios activos aplicados para las diferentes enfermedades que se presentaron en ambas campañas.

\begin{tabular}{|c|c|c|c|c|}
\hline \multirow{2}{*}{ Principio activo/fungicida } & \multirow{2}{*}{ Plaga objetivo } & \multicolumn{3}{|c|}{$\mathrm{N}^{\mathrm{o}}$ de aplicaciones } \\
\hline & & 2015 & 2016 & 2017 \\
\hline Aceite esencial de árbol de té Melaleuca artenifolia & & 1 & 5 & 2 \\
\hline Azoxistrobina + difenoconazole + oxicloruro de cobre & & 3 & 3 & 0 \\
\hline Azoxistrobina & & 0 & 0 & 1 \\
\hline Benomil + oxicloruro de cobre & & 3 & 0 & 0 \\
\hline Bacillus subtilis + Trichoderma harzianum/viride & & 0 & 3 & 0 \\
\hline Captan + promicidone & & 3 & 1 & 0 \\
\hline Clorotalonil & mancha gris Botrytis cinérea, & 0 & 0 & 3 \\
\hline Clorotalonil + azoxistrobina + difenoconazole & tizón foliar Sthemphyllium solani & 3 & 1 & 0 \\
\hline Iprodiona + oxicloruro de cobre & y el moho foliar del tomate & 3 & 0 & 0 \\
\hline Hidróxido de cobre & Cladosporium fulvum. & 0 & 0 & 2 \\
\hline Mancozeb & & 0 & 0 & 2 \\
\hline Procimidone + oxicloruro de cobre & & 3 & 1 & 0 \\
\hline Tebuconazole & & 0 & 3 & 2 \\
\hline Tridimefon & & 1 & 0 & 0 \\
\hline Pyraclostrobin + Boscalid & & 0 & 0 & 2 \\
\hline Trifloxistrobin + Tebuconazole & & 0 & 0 & 2 \\
\hline Total de aplicaciones realizadas & & 20 & 17 & 16 \\
\hline
\end{tabular}

facilitó el control de esta plaga siempre que el número de adultos y larvas de polilla estuvo por debajo del umbral de daño.

En cuanto a los trips y pulgones, se detectaron algunos focos solamente en la primera semana del trasplante que fueron controlados eficazmente con la aplicación localizada de productos botánicos. A pesar de que se registraron trips en las hojas de tomate en el monitoreo, la única especie que se encontró fue $C$. phaseoli, que no es vector del TSWV y, por consiguiente, no se detectó ningún síntoma en plantas durante las dos campañas.

Las enfermedades que más afectaron al cultivo fueron C. fulvum, B. cinérea y S. solani. La aplicación del MIPE logró una reducción del uso de fungicidas de síntesis química y, aunque el número de aplicaciones no disminuyó significativamente con respecto a la primera campaña, algunos de los extractos y aceites esenciales botánicos utilizados colaboraron al controlar la enfermedad por su particular composición.

En síntesis, la utilización de estas diferentes técnicas ha logrado reducir la aplicación de productos de síntesis química destinados a controlar plagas y enfermedades.

\section{Agradecimientos}

Este trabajo pudo ser realizado gracias al apoyo de:

1) Proyecto específico INTA - PNHFA 1106082. "Tecnología apropiada para la sustentabilidad con énfasis en sistemas hortiflorícolas con énfasis en cultivos protegidos".

2) REDAE Red de Agroecología - INTA.

3) Proyecto Regional con Enfoque Territorial INTA - PRETERIOS 1263305.

"Contribuir al desarrollo socioeconómico del noreste de Entre Ríos, en un marco de competitividad, salud ambiental y equidad social".

4) A la familia del productor Víctor Campeglia, que siempre me recibió con buena disposición y permitió la realización del trabajo.

5) A la traductora pública en Inglés Mónica Castresana, por sus observaciones y correcciones.

6) Al Ing. Agr. Javier Rosenbaum por el uso del vehículo asignado a PROHUERTA en los momentos en que no había disponibilidad de otros. 


\section{Literatura Citada}

Byrne, D.N.; Bellows Jr., T.S.

1991. Whitefly biology. Annual Review of Entomology, 36 (1): 431-457.

Castresana, J.E.; Paz., M.R.

2007. Parasitoides de Trialeurodes vaporariorum (Westwood) (Hemiptera: Aleyrodidae) en cultivos de Capsicum annum y Lycopersicum esculentum en el área de Concordia - Entre Ríos. Libro de Resúmenes $30^{\circ}$ Congreso Argentino de Horticultura $/ 1^{\circ}$ Simposio Internacional sobre Cultivos Protegidos. 25-28 de septiembre. La Plata, Buenos Aires, Argentina. pp. 362.

Ehler, L.E.

2006. Integrated pest management (IPM): definition, historical development and implementation, and the other IPM. Pest Management Science, 62(9): 787-789.

El-Sayed, A.M.; Suckling, D.M.; Wearing, C.H.; Byers, J.A. 2006. Potential of mass trapping for long-term pest management and eradication of invasive species. Journal of Economic Entomology, 99(5): 1550-1564.

Frank, K.D. 2006.

Effects of artificial night lighting on moths. In: Rich, C.; Longcore, T. (Eds.), Ecological Consequences of Artificial Night Lighting. Island Press. Washington DC, US. pp. 305-344.

Gu. X.S.; Bu. W.J.; Xu, W.H.; Bai, Y.C.; Liu, B.M.; Liu, T.X. 2008. Population suppression of Bemisia tabaci (Hemiptera: Aleyrodidae) using yellow sticky traps and Eretmocerus $n$ r. rajasthanicus (Hymenoptera: Aphelinidae) on tomato plants in greenhouse. Insect Science, 15 (3): 263-270.

Kaas, J.P.

2005. Vertical distribution of thrips and whitefly in greenhouses and relative efficiency of commercially available sticky traps for population monitoring. Proceedings of the Netherlands Entomological Society Meeting, 16 (10): 109-115.

Kogan, M.

1998. Integrated pest management: Historical perspectives and contemporary developments. Annual of Review Entomology, 43 (1): 243-70.

Mercado Central de Buenos Aires.

2011. Boletín electrónico En tomate. № 25. MCBA-INTA. 9 p.

Moschetti, R.

2003. Biological control using beneficial insects. Biological Control Bulletin. IPM of Alaska. Disponible en:www. ipmofalska.com. Consultado: 26/Jun/2017.

Park, J.J., Lee, J.H., Shin, K.I., Lee, S.E. \& K. Cho.

2011. Geostatistical analysis of the attractive distance of two different sizes of yellow sticky traps for greenhouse whitefly,
Trialeurodes vaporariorum (Westwood) (Homoptera: Aleyrodidae), in cherry tomato greenhouses. Australian Journal of Entomology, 50 (2): 144-151.

Polack, L.A.

2005. Manejo integrado de moscas blancas. Boletín Hortícola. 10 (31): 23-30.

Polack, L.; Mitidieri, M. (Ex Aequo).

2005. Producción de tomate diferenciado. Protocolo preliminar de manejo integrado de plagas y enfermedades. EEA San Pedro, INTA. Bs. Ar., Argentina. 19 p.

Prokopy, R.J.; Kogan

2003. Integrated pest management. In: Cardé, R.T.; Resh, V.R. (Eds.). Academic Press. San Diego, California, USA. pp. 589-595.

Qiao, M.; Lim, J.; Ji, C.W.; Chung, B.K.; Kim, H.Y.; Uhm, K.B.; Myung, C.S.; Cho, J.; Chon, T.S.

2008. Density estimation of Bemisia tabaci (Hemiptera: Aleyrodidae) in a greenhouse using sticky traps in conjunction with an image processing system. Journal of Asia Pacific Entomology, 11: (1) 25-29.

Qiu, B.L.; Ren, S.X.

2006. Using yellow sticky traps to inspect population dynamics of Bemisia tabaci and its parasitoids. Chinese Bulletin of Entomology, 43 (1): 53-56.

Soto, A., Estay, P.; Apablaza, J.

2002. Parasitismo de Encarsia formosa (Hymenoptera: Aphelinidae) en ninfas de Trialeurodes vaporariorum (Homoptera: Aleyrodidae). Revista Latinoamericana de Ciencias de la Agricultura, 29 (3): 153-157.

Van Driesche, R.G. \& T.S. Bellows Jr.

1996. Biology of arthropod parasitoids and predators, Biological Control. Springer. pp. 309-336.

Van Driesche, R.G.; Hoddle, M.S.; Center, T.D.

2007. Control de plagas y malezas por enemigos naturales. USDA. US. 751 p.

Vernon, R.; Gillespie. D.R.

1990. Response of Frankliniella occidentalis (Thysanoptera: Thripidae) and Trialeurodes vaporariorum (Homoptera: Aleyrodidae) to fluorescent traps in a cucumber greenhouse. Journal of the Entomological Society of British Columbia, 87: $38-41$.

Weatherston, I.

1990. Principles of design of controlled-release formulations. Behavior modifying chemicals for insect management applications of pheromone and other attractants. In: Ridgway, R.L.; Silverstein, R.M.; Inscoe. M.N. Marcel Dekker Inc. New York, USA. pp. 93-112. 
